Europe's Journal of Psychology 4/2009, pp. 40-51

www.ejop.org

\title{
Memory as a mediator between Depression and Academic achievement among Iranian Adolescents
}

\author{
Fayegh Yousefil Marof Redzuan², \\ Mariani Bte Mansor2 ${ }^{2} \quad$ Mansor Abu Talib2, \\ Rumaya Bte Juhari2
}

1- Department of psychiatry, Faculty of Medicine, Kurdistan University of Medical Science, Pasdarran St., Sanandaj-Iran

2-Faculty of Human Ecology, Universiti Putra Malaysia

\begin{abstract}
The purpose of this paper is to determine the mediation effect of memory on the relationship between depression and academic achievement. The paper is based on a study, which was carried out among adolescents in Iran. The respondents of the study were 400 adolescents (200 males and 200 females) in the age range of 15-19 years old. Instruments used for data collection were the Beck Depression Inventory (21 items) and the Wechsler Memory Scale - 3rd Edition (WMS-III). The finding shows that depression significantly affected academic achievement and this relationships is mediated by memory $(Z=1.65, p \leq 0$.). Thus, it is recommended to enhance academic achievement and mental health in school settings, support strategies such as educational guidance and counseling. Teaching life skill programs and psychotherapy should be promoted.
\end{abstract}

Keywords - Depression, Memory, Adolescents, Academic achievement

Introduction

Education is vital for every country in the world, and Iran is not an exception; a strong and effective education can help boost the development of the country. However, academic failure is one of the major problems the families, society and government. 
Furthermore, the rate of academic failure among high schools students is high in Iran. For instance, Amin Far (2002) found that 65 percent of students (girls) from rural areas and 34 percent of students (boys) from urban areas experience academic failure. According to the Education Organization of Sanandaj (2007), 27 percent of high school students have academic problems. Also, 28 percent, 27 percent and 11.55 percent of them in first grade, second grade, and third grade respectively had dropped out of school. In addition, Hamidian (2006) indicated that USD 50 million is needed to solve academic failure in western Azerbaijan Province in Iran.

Many factors affect academic achievement. One of them is depression. Depression has a high prevalence and relationship with both memory and academic achievement. Depression markers are: persistent sadness, discouragement, loss of self-worth and interest in daily activities. True depression in teens is often difficult to diagnose because normal adolescent behavior is marked by both up and down moods. These moods may alternate over a period of hours or days (Mackenzie, Gover, Armstrong \& Mitchell, 2001). Depression has an effect on academic achievement. Research has indicated that depressed mood is negatively related to academic achievement (Chen and Li, 2000, and Sanders, 2001, cited in, Modabber-Nia, Moosavi \& Fallahi, 2006). Thus, the major aim of the current study is to describe the role of depression on academic achievement mediated by memory.

\section{Literature review}

\section{a) Depression among adolescents}

It was estimated that 14 percent of the adolescents aged 12 to 17 (approximately 3.5 million adolescents) had a major depressive episode (MDE) in their lifetime, and an estimated of 9.0 percent (2.2 million adolescents) experienced at least one MDE in the past year. American adolescents aged 16 or 17 were more than twice as likely to report past year MDE as compared to those aged 12 or 13 (12.3\% vs. $5.4 \%$ ) in 2004 (Hallfors, Waller, Baver, Ford \& Halpern, 2005; Rockville, 2005) It is important to realize that many factors such as cultural, location, and samples differences are related to prevalence of depression. A piece of research which used Beck's depression questionnaire found that 34 percent of the respondents suffered from depression among 4020 high school students in Rasht, north of Iran (Modabber-Nia et al., 2006). Hossaini and Mousavi (2004) found that 44.3 percent of the high school students, and Masood Zadeh (2002) found that 39.1 percent of high school students in Iran had depression. Also, Ghahari (2004) reported that 27 percent of students were depressed in Iran .While, Frojd, Nissinen \& Pelkonen et al. (2008) indicated that the rate of depression among American adolescents were 18.4 percent for girls and 11.1 for percent boys. 
Similarly, another survey in USA which used a summarized self-administered Beck's questionnaire, reported severe depression in 18 percent of 8,206 adolescents (Kandel \& Davies, 1988; cited in Modabber-Nia et al., 2006).). Although the rate of depression seemed to be higher in those with low socio-economic status, there is no strong evidence to support this hypothesis (Akiskal, 2000; Murray, Lopez \& Hughes, 1998; Poznanski \& Mokros, 1994; cited in Modabber-Nia et al., 2006).

b) Depression, memory and academic achievement

From his research, Airaksinen, Wahlin, Forsell and Larsson (2006) found that depression has an impact on memory performance among respondents. Moreover, Pine, Lissek, Klein et al. (2004) indicated that there were significant relationships between memory performance, age and gender. Data from their study showed that there were associations between memory performance and major depression $[F(2,351)=3.3 ; p<.05]$, mean that depression significantly decreased memory performance. Furthermore, Park, Goodyear \& Teasdle (2002) found that depression affected and impaired the memory capacity among adolescents. In addition, Mowla, Ashkani, Ghanizadeh, Dehbozorgi, Sabayan \& Choherdri (2007) showed that memory performance, through subtests of the Wechsler Memory Scale-III, was related to depression. In addition, Torzandjani (2006) found that depression impacted on sub- divisions of memory such as mind control, visual memory and learning of association. It means that depression impairs attention and concentration. To elaborate this process, information processing theory (Atkinson and Schifrin, 1968) is employed to explain the effect of depression on memory. According this theory, when concentration and attention are impaired, short term memory could not transfer information to long term memory. As mentioned above, depression prevents the transferring of information from short-term memory to longterm memory. In other words, for transformation of information from short-term memory to long-term memory; students must focus attention and concentration. At this stage, depression disrupt this process, and therefore, memory is impaired due to inability to memorize and recall the information (Eggen \& Kauchak, 2004; Raulin et al., 2003).

Moreover, depressed people with and without memory complaints had lower scores on the Wechsler Memory Scale-III than the control group. Furthermore, Rohing \& Cogin (1993) found that depression has an impact on memory dysfunction, especially in older adults.

Similarly, An de Decker, Hermans, Raes and Eelen (2003) showed that depression, anxiety, worry, hopelessness, or subjective stress, were significantly related to the retrieval of specific memories. Also, Afshar (2004) found that mean of memory which 
was measured by Wechsler Memory Scale -3rd Editions (WMS-III) in depressed, Alzheimer and normal groups was 47, 37 and 55 respectively.

Annett, Bender \& Gordon (2007) in their study in the USA with 939 children ages 6-12 years old without neuropsychological problems, showed that memory was strongly related to academic achievement ( $\mathrm{p} \leq .001)$.

Meanwhile, Annett, Bender, \& Gordon (2007), in their study among 939 children with 6-12 years old without neuropsychological problems in America, found that memory was strongly related to academic achievement $(p \leq .001)$. Moreover, Wilding, Andrews \& Heidelberg (2007), in their study among 90 undergraduate students in United Kingdom, found that there were correlations between working memory and second year examination performance. In addition, Schwartz \& Gorman (2003) in their study with 199 elementary students at USA; Wintre \& Colleen, (2007) ; Newman, Griffen,, O'Connor \& Spas (2007), reported that depression was related to academic achievement .

\section{Research methodology}

This study was carried out in Sanandaj, Iran. The population of the study consisted of 33 high schools in Sanandaj Province. Nine schools were selected randomly. From these schools, 400 students (in the age range of 15-19 years old) were selected randomly as the respondents of the study.

Depression was measured using the Beck Depression Inventory (BDI). The Beck Depression Inventory is a 21 -item self-report rating inventory measuring the characteristic attitudes and symptoms and level of depression among respondents (Beck, Steer, and Garbin, 1988).The respondents were asked to answer each of the questions expressing their current feeling. The internal consistency for the BDI ranges from 0.73 to 0.92 with a mean of 0.86 (Beck et al., 1988). Similar reliabilities have been found for the 13-item short form (Groth-Marnat, 1990). The BDI demonstrates high internal consistency with Cronbach's alpha co-efficient of 0.86 and 0.81 for psychiatric and non-psychiatric populations respectively (Beck et al., 1988). In this study, BDI was adapted for Iranian culture (Mansour \& Dadsetan, 1988). According to Mohammad-Jafar Modabber-Nia et al. (2007), Beck's standardized questionnaire scores are defined as follows:

Symptom-free or normal $(0-15)$

Mild depression (16-30) 
Moderate depression (31 - 46)

Severe depression $(47-63)$.

Meanwhile, memory was measured by Wechsler Memory Scale -3rd Edition (WMSIII). The reliability coefficients for the WMS-III Primary Subtests and Primary Indexes were on average found to be higher than the WMS-R. Internal consistency reliability coefficients ranged from 0.70 s to the 0.90s. In addition, data from the current study shows the reliability of the WMS-III, based on Cronbach's Alpha, was 0.68.

In terms of academic achievement, the study follows the rules of the Ministry of Education in Iran, in which the Cumulative Grade Point Average (CGPA) is categorized into four categories: 0 to 9.99 is considered fail; score of 10 to 14.99 is considered as weak; score of 15 to 16.99 is considered as moderate, and finally, score of 17 to 20 is considered as excellent. Moreover, students were asked, about their previous year cumulative academic achievement (0.00-20.00).

The results of the study are presented as descriptive statistics, which include frequency and percentage distributions for level of depression and academic achievement variables. Statistical analyses employed in this study Sobel Test. This analysis is based on Baron \& Kenny's theory (1986), specifically to determine the mediation effect of memory on relationship between depression and academic achievement. According to Baron \& Kenny's theory (1986), there are four conditions regarding mediating variables. Firstly, the predictor must be significantly related to the outcome variable. Secondly, the predictor variable must be significantly associated with the mediator. Thirdly, the mediator must be significantly associated with the outcome variable. Finally, to establish the significance of the mediator, the relationship between the predictor and the outcome variables must be reduced after entering the mediator into the equation.

Results of the analysis

The respondents in the current study were 200 (50\%) male and 200 (50\%) female students. The age range of the respondents is 15 to 19 years old, and is divided into three categories - 43 percent aged 15 to 16;38 percent aged 17 to 18, and the last group, i.e. 17 percent aged 19 years old (see Table 1). Meanwhile, 3 percent of the respondents reported their academic achievement was less than 9.99, while 43.8 percent, 26.2 percent and 27 percent of them reported their academic achievement to be 10-4.99, 15-16.99 and more than 17, respectively (see Table 2). In terms of the level of depression experienced by the respondents, the results show 
that 70.5 percent of the respondents were symptom-free or normal, while 22.3 percent of them were mildly depressed, 3 percent of respondents were moderately depressed, and 2.8 percent of them had severe depression (insomnia, hypersonic, concentration and attention problems etc) .

Table 1: The age range of the respondents $(n=400)$

\begin{tabular}{lcc}
\hline Age range & $\mathbf{n}$ & $\%$ \\
\hline & & \\
$15-16$ & 174 & 43.5 \\
$17-18$ & 155 & 38.5 \\
$>19$ & 71 & 17.8 \\
\hline
\end{tabular}

Table 2: The academic achievement levels and depression level of the respondents

\begin{tabular}{|l|c|c|}
\hline $\begin{array}{l}\text { Academic achievement levels } \\
\text { (scores) }\end{array}$ & $\mathrm{n}$ & Percent \\
\hline 0-9.99 & 12 & 3.0 \\
\hline 10-14.99 & 175 & 43.8 \\
\hline 15-16.99 & 105 & 26.2 \\
\hline More than 17 & 108 & 27.0 \\
\hline Total & 400 & 100.0 \\
\hline & & \\
\hline Depression levels (scores) & & \\
\hline 0-15 (symptom-free or normal) & 282 & 70.5 \\
\hline 16-30 (mild depression & 95 & 23.7 \\
\hline 31-46 (moderate depression) & 12 & 3.0 \\
\hline 47-63 (severe depression) & 11 & 2.8 \\
\hline Total & 400 & 100.0 \\
\hline
\end{tabular}

Table 3: The Sobel test results related to the influence of depression on academic achievement mediated by memory

\begin{tabular}{|l|l|l|l|l|}
\hline Mediated pathway & \multicolumn{4}{|c|}{ Standardized coefficients } \\
\hline Sobel test result & B & S.E. & Z & P \\
\hline Depression $\rightarrow$ Memory $\rightarrow$ Academic Achievement & $.053^{*}$ & $.027^{* *}$ & 1.65 & 0.04 \\
\hline Memory & $.065^{* * *}$ & $.021^{* * * *}$ & & \\
\hline
\end{tabular}

* The regression coefficient for the relationship between depression and memory.

** The standard error of the relationship between the depression and the memory.

*** The regression coefficient for the relationship between the memory and the academic achievement.

**** The standard error of the relationship between the memory and the academic achievement. 
Table 2 shows the result of Sobel test. The main purpose of the test was to determine the mediation effect of memory on relationship between depression and academic achievement. The result shows that memory mediates the relationship between depression and academic achievement. In other words, depression significantly affected academic achievement mediated by memory. $(Z=1.65, p \leq 0.04)$.

\section{Discussions}

The finding of the study shows that memory is an important mediating variable. The finding of this study implies that memory would mediate the relationship between depression and academic achievement. It means that depression had indirect effect on academic achievement mediated by memory. As mentioned earlier, $43.8 \%$ of respondents were labeled as weak and $3 \%$ of respondents as failed in 2008. Findings from the current study are different from the findings of Daskzan (2005); Mozafari (2003) \& Nosrati Shoar (2003). The differences might be due to different sample size, motivation of the students, school's activities, different objectives and design of the studies. For instance, in this present study, academic achievement was investigated in regard to depression and memory; meanwhile the previous studies were carried out only on factors of academic achievement, such as the rate of academic failure. Moreover, the samples of the study conducted by Nosrati Shoar (2003) were elementary students.

These findings confirm those of Pine et al. (2004), An de Decker (2003) and Park et al. (2002), who found that students with symptoms of depression are predisposed to focus their attention on interfering, irrelevant thoughts, leaving little sustained attention available for cognitive tasks which leads to academic failure. Many of the school activities and homework depend on the ability to sustain attention and concentration. Thus, depression disrupts concentration and attention in school which, consequently, is likely to undermine academic performance, and also, researchers indicated that depressed mood is negatively related to academic achievement (Chen \& Li 2000, and Sanders 2001, cited in Needham, 2006).

In addition, depression is one of the mental disorders which bring many problems for a society, especially high school students. The current study shows that around 30 percent of the respondents were depressed. These results, however, were different from other research. For instance, based on Hallfors et al. (2005), it was estimated that 14 percent of the adolescents aged 12 to 17 had experienced at least one major depressive episode (MDE) in their lifetime, and an estimated of 9.0 percent of them experienced at least one MDE in the past. Adolescents aged 16 or 17 were 
more than twice as likely to report past MDE compared to those aged 12 or 13 (12.3 $\%$ vs. $5.4 \%$ ). The current study, also, differs from the studies by Modabber-Nia et al. (2006), Hossaini Mousavi (2004) and Masood Zadeh et al. (2002). The disagreement may be related to the using of different tools for measurement of depression, different sample size, motivation of respondents to respond, and the subjects' lifestyle. On the other hand, it is important to note that depression among high school students in the current study and other Iranian studies (Modabber-Nia et al., 2006; Hossaini \& Mousavi, 2004, and Masood zadeh et al., 2002) found the prevalence of depression in Iran more than the other countries such as USA and England. This difference may be related to cultural differences concerning psychosocial stress, and difference in the application of concepts such as self evaluation, social self-confidence, and adaptive behavioral styles (Modabber-Nia et al. 2006). This might also related to the type of their view regarding the self and the world. For example, based on the Beck depression theory (1977), negative view about self, future and world would lead to low self esteem, hopelessness and depression.

However, the result of the present study is in agreement with the results of the study carried out by Annett et.al (2004), who found that, there was a significant relationship between depression and memory performance $[F(2,351)=3.3 ; p \leq .05]$. In addition, the results of the present study also confirm with the results of the studies by Park et al. (2002) and Mowla et al. (2007), who indicated that depression has an impact on memory. Park et al. (2002) showed that depression had impact on memory among adolescents. In addition, Mowla et al. (2007) reported that depression affects memory performance.

\section{Conclusion}

The present study has proved that memory is a significant mediating variable between depression and academic achievement. In other words, among adolescents, memory is mediated between depression and academic achievement. The finding of this study implies that depression among adolescents could affect their learning process and other school activities. Moreover, depression could affect their learning motivation, and also their ability to pay attention and concentration in learning, and this could lead to academic failure. Thus, authorities that are concerned with the academic achievement of the children should take preventive actions, such as developing programs related to counseling and psychotherapy. To prevent the incidence of depression among students, the Ministry of Education should organize practical programs such as individual and group 
counseling. These programs could help and support students, where they can increase their abilities to perform better in school.

\section{References}

Afshar, H. (2004). Compression of Memory in depressed, Alzheimer and normal groups, PhD Thesis, Iran University of Medical Science and Health Services.

Ahmadian, T. (2005). The relationship between academic failure and mental disorders among the high school students. Kerman University of medical science.

Annett, R.D., Bender, G.B, \& Gordon, M. (2007). Relating children's' intentional capabilities to intelligence, memory and academic achievement: A test of construct specificity in child neuropsychology. 13, 6485.http://www.psypress.com/childneuropsych.

Airaksinen, E ., Wahlin, Å. Forsell,Y.\&. Larsson,M. (2006). Low episodic memory performance as a premorbid marker of depression: evidence from a 3-year follow-up. Acta Psychiatrica Scandinavica (Online Early Articles).

Amin Far, M. (2002). Academic failure among student. Journal of Educational Psychology, 2, 7-8.

An de Decker, H. D, Raes, F. \&Eelen, P.(2003) Autobiographical memory specificity and trauma in inpatient adolescents. Journal of Clinical Child and Adolescent Psychology, 32:22-31.

Beck,A.T., Steer,R .A , \& Garbin,M.G. (1988). Psychometric properties of the Beck depression inventory: Twenty-five years of evaluation. Clinical Psychology Review, 8, 77-100.

Baron, R. M. \& Kenny, D. A. (1986). The moderator-mediator variable distinction in social psychological research, Conceptual, strategic, and statistical considerations. Journal of Personality and Social Psychology, 51:1173-1182.

Daskzan. J.(2004). Prevalence of test-anxiety and its' related to academic problems. Research Center of Organization Education in Kurdistan province.

Education Organization of Sanandaj. (2007). Adolescents population at the Kurdistan Province, Sanandaj-Iran. 
Eggen and Kauchak .(2004).Educational psychology . USA: Merril Prentice Hall Press.

Frojd, S.A., Nissinen, E.S., Pelkonen ,M.U.I.,Marttuenb, M.j, Koivisto,A.M., \& KaltialaHeino,K. (2008). Depression and school performance in middle adolescent boys and girls. Journal of Adolescence 31: 485-498.

Ghahari, S.H. (2004).The prevalence rate of depression among college students in Iran. International Journal of mental health and addiction, 1705-458.

Groth-Marnat, G. (1990). The handbook of psychological assessment. New York: John Wiley \&Sons.

Hosseini,S.H. \& Mousavi,S.E.(2004).Mental-Health Status of Newly-Admitted Students of the Mazandaran University of Medical Sciences in the 1999-2000 Academic Year, Published online November 7, 2004.

Hamidian,H. (2006). Academic failure in Azerbaijan province, Iran, News agency of Islamic Republic of Iran.

Hallfors,D.D., Waller,M.W., Baver,D., Ford,C.A., \& Halpern,C.T. (2005). Adolescence, sex and drugs or depression. American. Journal of preventive medicine 29:163-170.

Mowla,A., Ashkani,H.,Ghanizadeh,A,. Dehbozorgi,GR., Sabayan,B\& Chohedri,AH. (2007). Do memory complaints represent impaired memory performance in patients with major depressive disorder, Retrieved. From.

MacKenzie, D. L., Gover, A.R., Armstrong, G.S.\&Mitchell, O. (2001). A national study comparing the environments of boot camps with traditional facilities for juvenile offenders (Publication. from Washington, DC. National Institute of Justice.

Mozaffari, M. (2001). Rate of affective-family and educational problems between Shaheds'high school students and none Shaheds'high school students in Sanandaj. Organization Education of Kurdistan.

Masood zadeh.J. (2001). Paper presented at the Fourth National Seminar of Mental Health and Mental Behaviors of Adolescents and Children.

Modabber-Nia,J.M.,Asli,N.J., Moosavi,S.R.,Fallahi, M. (2006). The prevalence of depression among high School and pre-university adolescents: Rasht, northern Iran. Archives of Iranian Medicine, 2, 141 - 146. 
Mansour M \& Dadsetan P. (1988). Mental disorders. 2nd ed. Tehran: Zharf: Appendix. (Persian).

Nosrati Shoar,M. (2003). Causality of academic problems among elementary school students in Kurdistan- Iran. Organization Education

Needham,B.L. (2006). Gender differences in the consequences of depressive symptomatology for educational attainment, social support, and health risk behavior during the transition from adolescence to young adulthood, PhD thesis, University of Texas.

Newman, B., Newman, Griffen, O'Connor and Spas. (2007). The relationship of social support to depressive symptoms during the transition to high school. Journal of Adolescence, 42, 167.

Pine,D.S., Lissek,S., Klein,R.G., Mannuzza,S., Moulton,J.L., Guardino, M. and Woldehawariat,G. (2004). Face-memory and emotion: associations with major depression in children and adolescents. Journal of Child Psychology and Psychiatry, 45: 1199-1208.

Park, R. J., Goodyear, I. M. \& Teasdale, J. D. (2002). Categorical over-general autobiographical memory in adolescents with major depressive disorder. (Vol. 32). Cambridge: Cambridge University Press.

Raulin, L., \& Ktkin.( 2003). Abnormal psychology. New York: Alyn and Bacon Press.

Rohling, M. L., \& Scogin, F. (1993). Automatic and effortful memory processes in depressed persons. Journal Gerontology, 2, 87-95.

Schwartz,A.\& Gorman,A.H .(2003). Community violence exposure and children's academic functioning, Journal of Educational Psychology 95 (No. 1), 163-173.

Torzandjani, H. (2006). Memory based on logic with mood among depressed people. University of Nayshapoor- Iran.

Wilding,B. \& Hedenberg. (2007). Relations between life difficulties, measures of working memory operation, and examination performance in a student sample (Vol. 15) Psychological Press. 
Winter ,M.G. \& Bowers,C.D. (2007). Peer relationships and academic achievement as interacting predictors of depressive symptoms during middle childhood. Canadian Journal of Behavioral Science 39: 220-234. 